\title{
Perbandingan trajectory tracking pada prototype excavator sistem pneumatic dengan sistem kontrol menggunakan joystick dan smartphone android
}

\author{
Randis $^{1^{*}}$, Angga Wahyu Aditya ${ }^{2}$ \\ Jurusan Teknik Mesin, Program Studi Alat Berat, Politeknik Negeri Balikpapan ${ }^{1}$ \\ Jurusan Teknik Elektro, Program Studi Teknik Lestrik, Politeknik Negeri Balikpapan² \\ Jl. Soekarno Hatta Km. 8, Balikpapan \\ Email: randis@poltekba.ac.id'1 , Angga.wahyu@poltekba.ac.id ${ }^{2}$
}

\begin{abstract}
Trajectory tracking testing is mostly implemented both on vehicles, mobile robots, flying robots, and excavators to generate a small value of trajectory tracking to effectiveness and efficiency by the tasks and functions of each unit or product. This study aims to compare trajectory tracking on pneumatic excavator units with a manual control system with a joystick and a remote control system using an Android smartphone. Two tracks are used where the first track uses combine straight and radius shapes and the second track combines horizontal and vertical lines that form an angle of $90^{\circ}$. The results showed the use of remote control using an Android smartphone still has a higher trajectory tracking error when compared to manual control with a joystick even though on average the error results obtained are small, so more remote control is needed.
\end{abstract}

Keywords: Pneumatic excavator system, joystick control system, remote control system, error trajectory tracking.

\begin{tabular}{|c|c|}
\hline \multicolumn{2}{|c|}{ Abstrak } \\
\hline $\begin{array}{l}\text { Pengujian trajectory tracking banyak } \\
\text { robot terbang, dan juga excvator untuk men } \\
\text { dihasilkan efektifitas dan efisiensi sesuai d } \\
\text { Tujuan dari penelitian ini untuk memband } \\
\text { pneumatik dengan sistem sistem kontrol mar } \\
\text { dengan menggunakan smartphone androic } \\
\text { lintasan pertama menggunakan kombinasi b } \\
\text { dengan kombinasi garis lurus horizontal } \\
\text { penelitian menunjukkan penggunaan kontr } \\
\text { android masih mimiliki error trajectory tra } \\
\text { kontrol manual dengan joystick meskipun } \\
\text { sehingoa dihutuhkan kontrol iarak iauh vano }\end{array}$ & $\begin{array}{l}\text { ukan baik pada kendaraan, mobile robot, } \\
\text { an nilai trajectory tracking yang kecil agar } \\
\text { tugas dan fungsi setiap unit atau produk. } \\
\text { trajectory tracking pada unit excavator } \\
\text { ngan joystick dan sistem kontrol jarak jauh } \\
\text { unakan dua track lintasan dimana pada } \\
\text { lurus dan radius dan track lintasan kedua } \\
\text { rtical yang membentuk sudut } 90^{\circ} \text {. Hasil } \\
\text { k jauh dengan menggunakan smartphone } \\
\text { jang lebih besar jika dibandingkan dengan } \\
\text { rata-rata hasil error yang diperoleh kecil, } \\
\text { ontrol joystick, sistem kontrol jarak jauh, }\end{array}$ \\
\hline $\begin{array}{l}\text { Pendahuluan } \\
\text { Alat berat termasuk excavator } \\
\text { merupakan suatu unit kendaraan yang } \\
\text { memiliki tugas berat yang memegang } \\
\text { peran penting dalam melaksanakan suatu } \\
\text { proyek dan operasi produksi. Excavator } \\
\text { banyak digunakan di berbagai jenis } \\
\text { pekerjaan seperti pertambangan, }\end{array}$ & $\begin{array}{l}\text { perkebunan, dan konstruksi karena } \\
\text { memiliki sifat yang ekonomi [1-2]. } \\
\text { Excavator hidrolik memiliki berbagai } \\
\text { keuntungan dari sisi peningkatan efisiensi } \\
\text { kerja [3], dengan menggunakan operator } \\
\text { yang berpengalaman dapat membuatnya } \\
\text { lebih efektif dan efisien dalam } \\
\text { pengoperasian termasuk mengurangi }\end{array}$ \\
\hline
\end{tabular}


beban kerja excavator secara keseluruhan [4].

Trajectory tracking tidak hanya dilakukan pada excavator tapi banyak digunakan pada robot terbang quadcopter dan helicopter [5-8]. Pelacakan lintasan dilakukan oleh [5], pada wilayah yang berangin sehingga bagaimana menjaga quadcopter untuk tetap pada jalurnya. Sementara pada [6-7] membangun dan mengembangkan PD-fuzzi control dan PID control pada quadcopter untuk melakukan pelacakan lintasan secara otomatis. Secara umum pelacakan lintasan pada pada quadcopter dimaksudkan untuk mencapai tujuan dengan waktu yang efektif dan efisien serta menjamin misi dapat diselesaikan dengan baik [8].

Trajectory tracking juga banyak dilakukan pada kendaraan roda empat maupun pada mobile robot [9-11], pada [9] menyajikan sebuah trajectory tracking pada sebuah kendaraan penumpang untuk mengikuti lintasan secara aman, sementara pada $[10,11]$ menyajikan sebuah kendaraan otomatis untuk $m$ elakukan tingkat kesalahan dalam pelacakan dijalanan secara actual. Untuk mobile robot telah mengaplikasikan sebuah control PI-type sliding surface and a switching control untuk menjajal acuan lintasan yang telah dibuat untuk memastikan tingkat keakuratan sistem kontrol dalam hal pelacakan lintasan [12]. penguajian error trajectory tracking pada mobile robot dilakukan untuk memastikan mobile robot untuk mengetahui kemampuan kontrol secara manual dengan menggunakan operator untuk memastikan error yang terjadi tidak terlampau besar [13].

Pada excavator, pengujian secara experimental untuk menguji trajectory tracking pada lintasan dari bucket excavator selama penggalian dilakukan guna peningkatan efisiensi dan produktivitas pada excavator [14-15]. Kontrol kendali jarak jauh dari sebuah excavator industri untuk penggalian loading dan dumping dengan system "kemudi bucket" yang mengikuti lintasan penggalian yang tipikal juga telah dikembangkan untuk untuk mengetahui tingkat efektifitas dan efisiensi dari sebuah excavator [16].

Penelitian yang dikembangkan yaitu dengan menggunakan prototype excavator dengan sistem pneumatic, sistem ini telah menggunakan sistem kontrol manual dengan joystick kemudian dikembangkan dengan sistem kontrol jarak jauh dengan menggunakan perangkat smartphone android. Selanjutnya dari kedua sistem kontrol ini, akan diuji secara experimental terhadap error trajectory tracking pada keduanya untuk memastikan tingkat pelacakan lintasan yang lebih kecil dan yang lebih baik sistem kontrolnya.

\section{Metode Penelitian}

1. Objek Penelitian

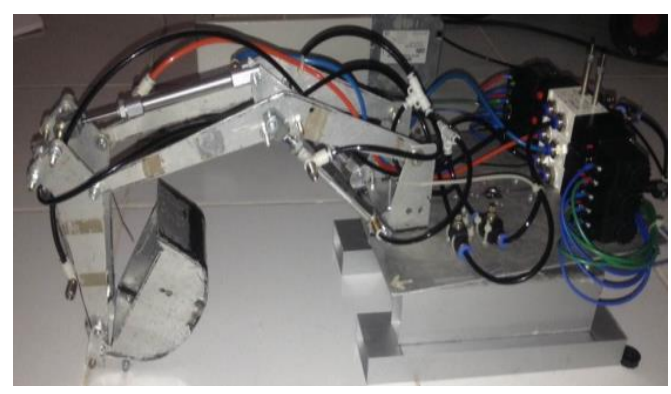

Gambar 1. Objek penelitian

Gambar 1 menunjukkan prototype excavator dengan menggunakan sistem pneumatik yang akan digunakan pada penelitian ini. Penelitian ini semakna dengan penelitian terdahuu [17] yang menggunakan objek yang sama. Secara sederhana system prototype excavator ini merupakan alat dengan menggunakan udara bertekanan (pneumatik) untuk menggerakkan actuator berupa silinder dan akan menggerakkan bucket sebagai end efectornya.

Rangkaian listrik digunakan untuk mengaktifkan solenoid yang ada pada control valve, angin bertekanan akan diarahkan diarahkan oleh control valve ke silinder untuk menggerakkan lengan pada 
alat excavator. Pada penelitian ini, alat akan dikontrol dengan dua system control yaitu system control secara manual menggunakan joystick dan kontrol yang kedua dengan menggunakan kontrol jarak jauh menggunakan perangkat smartphone android.

2. Sistem Kontrol Manual Joystick

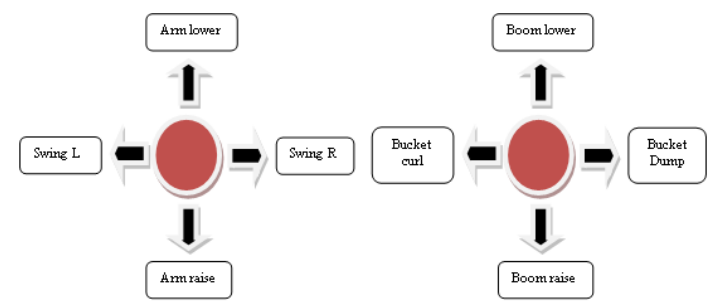

Gambar 2. Arah gerak kontrol joystick

Sistem control untuk mengontrol gerak pada excavator pneumatic menggunakan joystick switch. Joystick switch yang dipakai memiliki 4 limit switch normally open dan masing-masing limit switch berfungsi sebagai penghubung antara power supply sebagai sumber arus dengan komponen-komponen penggerak mekanik alat seperti solenoid control valve dan motor DC.

Arus listrik akan mengalir ke setiap komponen penggerak jika limit switch pada joystick dalam posisi normally close. Limit switch normally close bila tuas pada joystick diarahkan pada button limit switch. joystick switch yang digunakan berupa 4 buah limit switch pada setiap joystick, sehingga joystick dapat bekerja dalam 4 arah pengendalian sebagaimana ditunjukkan pada gambar 2 .

3. Sistem Kontrol Jarak jauh dengan Smartphone

Sistem kontrol jarak jauh dengan menggunakan smartphone menggunakan perangkat android yang menggunakan perangkat bantu aplikasi yang dibangun dengan menggunakan mit app invertor sebagaimana pada [18]. Pengendalian menggunakan perangkat smartphone android terhubung dengan perangkat mikrokontroller arduino yang sudah diprogram melalaui koneksi modul bluetooth seperti ditunjukkan pada gambar 3. Selanjutnya terdapat komponen relay 8 channel yang berfungsi untuk menggantikan saklar listrik sebagai pemicu terhubung ke selenoid sehingga dapat menggerakkan silinder pada prototype excavator pneumatik [17].

Perangkat mit app invertor adalah perangkat untuk membuat program aplikasi ponsel pinter berbasis Android [19], tampilan pada smartphone android ditunjukkan pada gambar 4 .

Program ini bila dijalankan di smartphone Android, akan mengirim sinyal ke modul bluetooth sebagaimana ditunjukkan pada gambar 3. Modul bluetooth meneruskan sinyal ini ke microkontroler melalui komunikasi serial. Pengontrolan dengan smartphone android sebagai pengendali dari excavator dan arduino sebagai mikrokontroller yang dihubungkan dengan modul bluetooth.
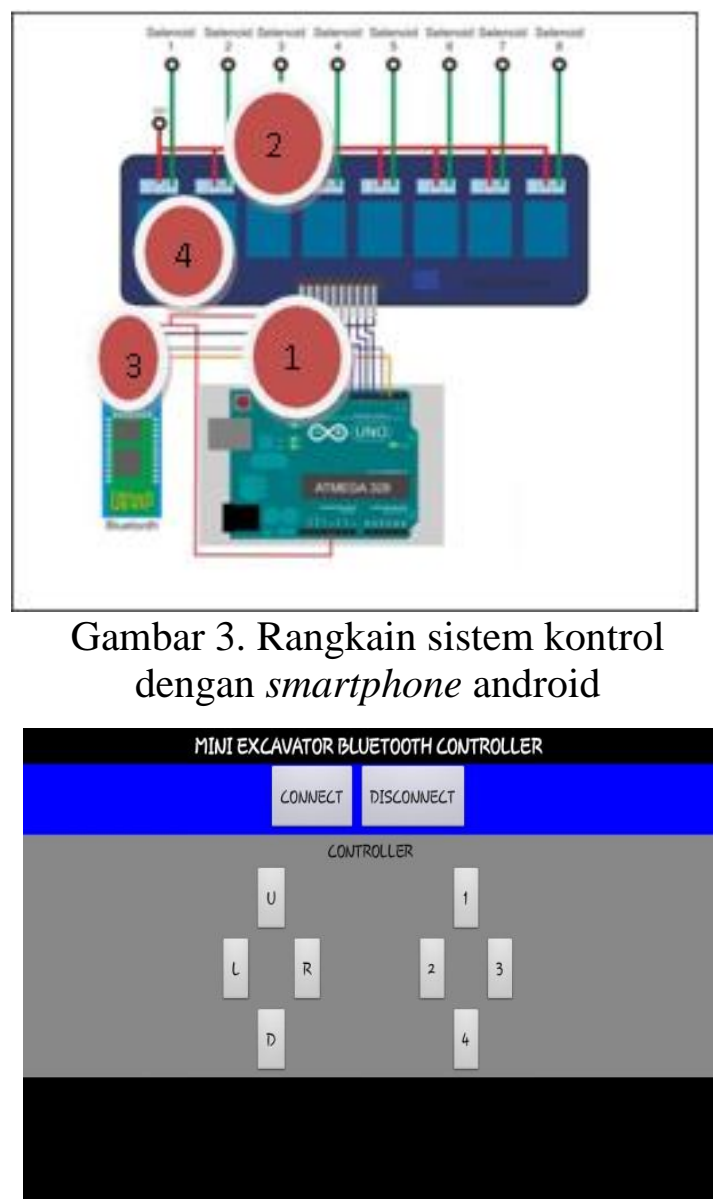

Gambar 4. Tampilan aplikasi pada smartphone android 


\section{Track Lintasan}

Metode penjejakan lintasan dilakukan sebagaimana pada $[13,20,21]$ pada $[13,20]$ menggunakan mobile robot dengan menggambar lintasan pada permukaan lantai kemudian mobile robot berjalan mengikuti litasan yang telah dibuat sebelumnya selanjutya diukur error trajektory tracking yang terjadi. Adapun pada [21] menggunakan quadcopter dengan menerbangkan quadcopter dan mencoba melakukan penelusuran lintasan pada permukaan lantai dan dilakukan pengukuran $[13,20]$. Adapun pada penelitian ini, Pembuatan track lintasan dilakukan pada pemukaan dinding vertical kemudian pada ujung bucket protype excavator ini akan dipasangkan sebuah pena kemudian dilakukan penjejakan lintasan selanjutnya mengukur error yang terjadi.

Pada penelitian ini menggunakan operator dengan kemampuan yang hampir sama dengan sistem kontrol yang berbeda (kontrol manual joystick dan kontrol jarak jauh menggunakan smartphone). Bentuk lintasan 1 yang harus dilewati ujung excavator ditunjukkan pada gambar 5, panjang lintasan $100 \mathrm{~cm}$ dengan bentuk kombinasi yaitu bentuk lurus dan radius. Adapun bentuk lintasan 2 diperlihatkan pada gambar 6 , panjang lintasan $75 \mathrm{~cm}$ bentuk kombinasi garis lurus vertical dan horizontal.

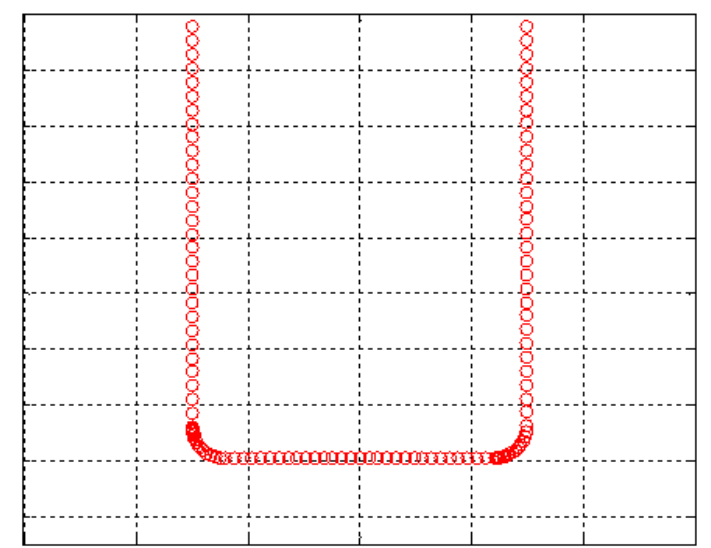

Gambar 5. Bentuk lintasan 1

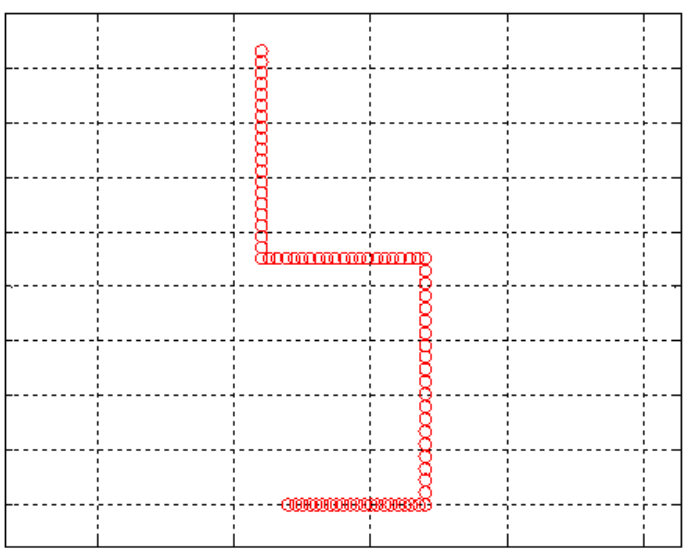

Gambar 6. Bentuk lintasan 2

\section{Hasil dan Pembahasan}

\section{Trajectory Tracking pada Lintasan 1}

Pengujian dan pengukuran trajectory tracking pada excavator sistem pneumatik pada lintasan 1 sebagaimana pada metode penelitian telah dilakukan. Terdapat dua buah sistem kontrol yang digunakan yaitu sistem kontrol manual dengan joystick dan sistem kontrol jarak jauh dengan menggunakan smartphone android dengan tingkat kemahiran operator yang hampir sama.

Hasil pengukuran error diolah dengan menggunakan sebuah software pengolah data dan plot grafik matlab dan ditunjukkan pada gambar 7 .

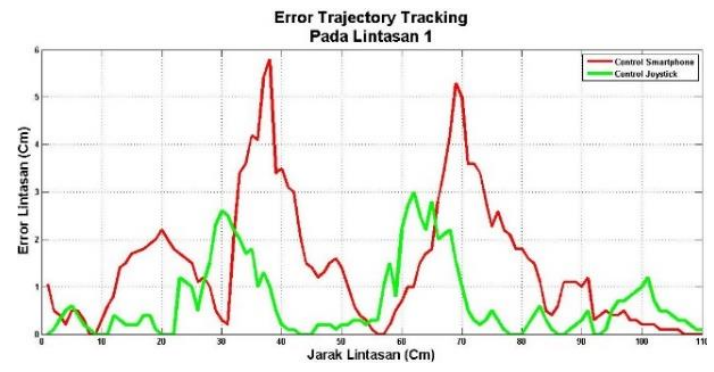

Gambar 7. Grafik Error Trajectory Tracking pada Lintasan 1

Pada grafik gambar 7 menunjukkan terjadinya peningkatan error mendekati jarak track lintasan di jarak $40 \mathrm{~cm}$ dan juga di jarak $70 \mathrm{~cm}$, setelah melihat bentuk lintasan pada gambar 5, maka diperoleh sebuah fakta bahwa setiap operator akan mengalami kesulitan dalam mengikuti track lintasan ketika terjadi perubahan bentuk lintasan dari bentuk lurus ke bentuk 
radius begitu juga sebaliknya, hal ini sama dengan hasil penelitian sebelumnya $[13,20,21]$, akan terjadi peningkatan yang cukup signifikan pada area lintasan yang berbelok dan membentuk radius ataupun lingkaran.

Nilai error terbesar pada operator yang menggunakan sistem kontrol jarak jauh smartphone yaitu $5,8 \mathrm{~cm}$ yang tejadi di jarak track lintasan $38 \mathrm{~cm}$ hal ini disebabkan oleh adanya perubahan bentuk lintasan lurus ke radius sehingga operator kurang dapat menyesuaikan kontrol dengan lintasn yang ada.

Sedangkan nilai error terbesar pada operator dengan sistem kontrol manual menggunakan joystick yaitu sebesar $2,9 \mathrm{~cm}$ di jarak $63 \mathrm{~cm}$ track lintasan dari posisi start. Hal ini disebabkan oleh operator yang ingin memperoleh haluan yang bagus dalam mengikuti track lintasan berbentuk radus namun malah menyimpang jauh dari titik acuan awal. Secara umum, sistem kontrol secara manual menggunakan joystick memiliki nilai error yang lebih kecil yaitu rata-rata $0,74 \mathrm{~cm}$, sementara untuk kontrol jarak jauh menggunakan smartphone rata-rata $1,5877 \mathrm{~cm}$. Nilai ratarata eror trajectory tracking pada track lintasan 1 secara keseluruhan yaitu:

$$
e_{\text {total }}=\sqrt{\frac{\sum_{0}^{n} e_{x}^{2}+\sum_{0}^{n} e_{y}^{2}}{n}} e_{\text {total }}=1,1638 \mathrm{~cm}
$$

\section{Trajectory Tracking pada Lintasan 2}

Pada lintasan 2 seperti terlihat pada gambar 6, track lintasan dimulai dengan garis lurus kemudian bergerak kearah kanan keemudian bergerak vertical kebawah dan terakhir berbelok kekiri membentuk sudut sebesar $90^{\circ}$ dengan jarak lintasan keseluruhan sebesar $75 \mathrm{~cm}$.

Pada gambar 6 track lintasan kedua terlihat bahwa error terbesar terjadi pada saat bucket mengikuti bentuk yang membetuk sudut $90^{\circ}$ pada belokan. Hal ini disebabkan karena pada saat bucket diarahkan berbelok melakukan transformasi (perubahan posisi) dari vertical ke horisontal membetuk sudut $90^{\circ}$ yang menyebabkan operator menjauh dari track lintasan sehingga mengakibatkan nilai error yang besar namun tidak sebesar jika bentuk lintasan berbentuk radius.

Gambar 8 menunjukkan hasil error trajectory tracking yang terjadi pada lntasan 2, error terbesar untuk kontrol dengan smartphone pada jarak lintasan 40 $\mathrm{cm}$ yaitu sebesar $2,5 \mathrm{~cm}$ sementara pada kontrol dengan joystick, error terbesar pada jarak lintasan $20 \mathrm{~cm}$ dengan nilai error sebesar $1,6 \mathrm{~cm}$.

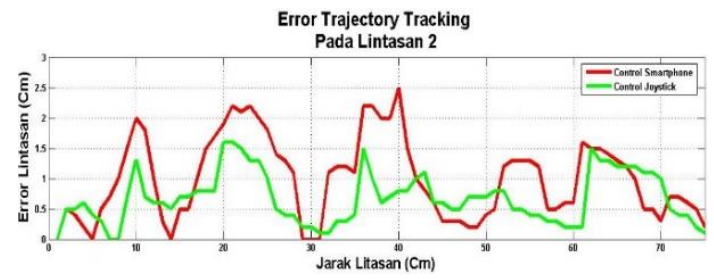

Gambar 8. Grafik Error Trajectory Tracking pada Lintasan 2

Pada track lintasan2, sstem kontrol secara manual menggunakan joystick memiliki nilai error yang lebih kecil seperti pada lintasan 1 yaitu rata-rata $0,675 \mathrm{~cm}$, sementara untuk kontrol jarak jauh menggunakan smartphone rata-rata 0,996 $\mathrm{cm}$. Nilai rata-rata eror trajectory tracking pada track lintasan 2 secara keseluruhan yaitu:

$$
e_{\text {total }}=\sqrt{\frac{\sum_{0}^{n} e_{x}^{2}+\sum_{0}^{n} e_{y}^{2}}{n}} e_{\text {total }}=0,83533 \mathrm{~cm}
$$

Jika dibandingkan dengan lintasan 1 , pada lintasan 2 ini memiliki rata-rata error trajectory tracking yang lebih kecil, hal ini disebabkan karena tidak adanya radius dan bentuk lintasan yang umumnya lurus sehingga memudahkan si operator dalam mengontrol dan mengikuti lintasan.

\section{Kesimpulan}

Penelitian ini telah melaporkan dan menyajikan error trajectory tracking bucket excavator system pneumatic pada dua track lintasan dengan dua sistem kontrol yang berbeda yaitu yaitu sistem kontrol manual dengan joystick dan sistem kontrol jarak jauh dengan menggunakan smartphone android. Penggunaan kontrol jarak jauh dengan menggunakan 
smartphone android masih mimiliki error trajectory tracking yang lebih besar jika dibandingkan dengan kontrol manual dengan joystick meskipun secara rata-rata hasil error yang diperoleh kecil, sehingga dibutuhkan kontrol jarak jauh yang lebih baik atau menggunakan sistem yang berbeda untuk mendapatkan error yang lebih kecil karena hal ini akan berpengaruh pada tingkat produksi dan efektifitas pada excavator jika telah digunakan pada tingkat industry.

\section{Referensi}

[1]. Simatupang, T.M. and Sridharan, R., 2016. A critical analysis of supply chain issues in construction heavy equipment. International Journal of Construction Management, 16(4), pp.326-338.

[2]. Yu, C., Ni, T., Lin, J., Zhou, D. and Shang, J., 2015. Visual and real-time simulation of dynamic cutting of earthmoving work. Transactions of the Chinese Society of Agricultural Engineering, 31(4), pp.217-223.

[3]. Tomatsu, T., Nonaka, K., Sekiguchi, K. and Suzuki, K., 2015, September. Model predictive trajectory tracking control for hydraulic excavator on digging operation. In 2015 IEEE Conference on Control Applications (CCA) (pp. 1136-1141). IEEE.

[4]. Van der Horst, I.A. and Mourik, R., 2010. Automating excavators to reduce cycle times and maintain safety \& accuracy. Proceedings WODCON XIX, Beijing, China.

[5]. Guerrero, J.A., Escareño, J.A. and Bestaoui, Y., 2013, May. Quad-rotor MAV trajectory planning in wind fields. In 2013 IEEE International Conference on Robotics and Automation (pp. 778-783).

[6]. Santoso, F., Garratt, M.A. and Anavatti, S.G., 2015, October. Fuzzy logic-based self-tuning autopilots for trajectory tracking of a low-cost quadcopter: A comparative study. In 2015 International Conference on Advanced Mechatronics, Intelligent Manufacture, and Industrial Automation (ICAMIMIA) (pp. 6469). IEEE.

[7]. Vílez, P., Certad, N. and Ruiz, E., 2015, October. Trajectory generation and tracking using the AR. Drone 2.0 quadcopter UAV. In 2015 12th Latin American Robotics Symposium and 2015 3rd Brazilian Symposium on Robotics (LARS-SBR) (pp. 73-78). IEEE.

[8]. Randis, R. and Akbar, S., 2017. Uji eksperimetal trajectory tracking pada quadcopter. DINAMIKA: Jurnal Ilmiah Teknik Mesin, 9(1).

[9]. Hima, S., Lusseti, B., Vanholme, B., Glaser, S. and Mammar, S., 2011. Trajectory tracking for highly automated passenger vehicles. IFAC Proceedings Volumes, 44(1), pp.12958-12963.

[10]. Werling, M., Groll, L. and Bretthauer, G., 2010. Invariant trajectory tracking with a full-size autonomous road vehicle. IEEE Transactions on Robotics, 26(4), pp.758-765.

[11]. Guo, J., Li, K. and Luo, Y., 2015. Coordinated control of autonomous four wheel drive electric vehicles for platooning and trajectory tracking using a hierarchical architecture. Journal of Dynamic Systems, Measurement, and Control, 137(10), p.101001.

[12]. Cao, Z.C., Zhao, Y.T. and Fu, Y.L., 2012. Trajectory tracking control approach of a car-like mobile robot. Dianzi Xuebao(Acta Electronica Sinica), 40(4), pp.632-635.

[13]. Syam, R., Ohoiwutun, J. (2013). Uji Eksperimen untuk Trajectory Tracking Mesin Pemotong Rumput Tenaga Surya. "Proceeding Seminar Nasional Tahunan Teknik Mesin XII (SNTTM XII). 
[14]. Gurko, A., Sergiyenko, O., Hipólito, J.I.N., Kirichenko, I., Tyrsa, V. and Hernandez, W., 2016. Trajectory Tracking Control of an Excavator Arm Using Guaranteed Cost Control. In Informatics in Control, Automation and Robotics 12th International Conference, ICINCO 2015 Colmar, France, July 21-23, 2015 Revised Selected Papers (pp. 177-196). Springer, Cham.

[15]. Da-qing, Z., Qing-hua, H., Peng, H. and Qian-gen, C., 2006. Robust trajectory tracking control of hydraulic excavator bucket. Journal of Jilin University: Engineering and Technology Edition, 36(6), pp.934938.

[16]. Liu, Y., Hasan, M.S. and Yu, H.N., 2010. Modelling and remote control of an excavator. International Journal of Automation and Computing, 7(3), pp.349-358.

[17]. Randis (2018). Prototype excavator with Pneumatic system Controlled Using Android Device, in Proceedings-2018 International Confrence on Applied Science and technology, Icast 2018.

[18]. Jivani, M.N., 2014. GSM based home automation system using appinventor for android mobile phone. International Journal of Advanced Research in Electrical, Electronics and Instrumentation Engineering, 3(9).

[19]. Khera, N., Tiwari, S., Singh, R.P., Ghosh, T. and Kumar, P., 2016, October. Development of android based smart home and nurse calling system for differently abled. In 2016 5th International Conference on Wireless Networks and Embedded Systems (WECON) (pp. 1-4). IEEE.

[20]. Randis, R., 2019. Uji eksperimetal trajectory tracking pada robot penjinak bom. Jurnal Integrasi, 11(1), pp.33-36.
[21]. Randis, R. and Akbar, S., 2017. Uji eksperimetal trajectory tracking pada quadcopter. DINAMIKA: Jurnal Ilmiah Teknik Mesin, 9(1). 